\title{
Nine Months to Progression Using Fourth-Line Liposomally Encapsulated Paclitaxel against Hepatocellular Carcinoma
}

\author{
Maximilian Christopeit ${ }^{b} \quad$ Georg Lenz $^{\mathrm{a}}$ Roswitha Forstpointner ${ }^{\mathrm{a}}$ \\ Kerstin Bartelheim ${ }^{c}$ Robert Kühnbach ${ }^{a}$ Kurt Naujoks ${ }^{d}$ Andreas Schalhorn ${ }^{a}$ \\ a Department of Medicine III, Hematology/Oncology, University Hospital Grosshadern, Medical Faculty, \\ Ludwig Maximilian University, Munich; ${ }^{b}$ Department of Medicine IV, Oncology/Hematology, \\ University Hospital Halle (Saale), Halle (Saale); ${ }^{c}$ Geltendorf; ${ }^{d}$ Bremen, Germany
}

\section{Key Words}

Hepatocellular carcinoma • Antiangiogenesis • Paclitaxel • Taxanes

\begin{abstract}
Background: Hepatocellular carcinoma (HCC) is the third most common cause of cancer deaths. Difficulties to diagnose HCC at early stages remain the major obstacle to curative (surgical) therapy. Therapy in advanced stages has to be considered palliative. In this situation, a considerable amount of attention should be paid to innovative treatment strategies, e.g. including antiangiogenetic drugs. Results: We report on the successful treatment of a patient suffering from progressive HCC with a novel drug (EndoTAG ${ }^{\circledR}-1$, formerly named LipoPac ${ }^{\circledR}$ ) currently investigated in phase II studies. This drug consists of liposomally encapsulated paclitaxel. Its liposomal formulation favors the drug's adherence to the tumor neovasculature, in effect starving the tumor. Conclusions: EndoTAG ${ }^{\circledR}-1$ stopped tumor progression for 9 months in our patient. This, along with successes observed testing this drug against other indications, makes it a suitable candidate for future clinical trials. Copyright $\odot 2008$ S. Karger AG, Basel
\end{abstract}

\section{KARGER \\ Fax +41613061234 \\ E-Mail karger@karger.ch}

www.karger.com
(C) 2008 S. Karger AG, Basel

0009-3157/08/0544-0309\$24.50/0

Accessible online at:

www.karger.com/che

\section{Introduction}

Primary liver cancer is the fifth most common cancer worldwide [1]. As almost every affected individual dies, it is the third most common cause of cancer deaths worldwide [1]. Liver cirrhosis is the strongest predisposing factor for the development of a HCC [2]. On the basis of estimates of the burden of hepatocellular carcinoma (HCC) in the US, fears arise that during the next two decades the incidence in the US might increase to meet the incidence currently observed in Japan [3]. This rise is mainly attributed to the increasing spread of viral hepatitis [4]. Amongst the well-defined major risk factors, alcohol abuse is a further leading cause for the development of HCC. Intake of aflatoxin via contaminated food, too, and different metabolic disorders are associated with an increased risk for this hazard. As vaccination against hepatitis $\mathrm{B}[5,6]$ helped to reduce the prevalence of HCC, prevention of hepatitis $\mathrm{C}$, the most prominent risk factor for the development of HCC in developed countries, or delay of the disease's progress [7], are hoped to further reduce the prevalence of HCC. Novel treatment strategies against HBV might help to lower this diseases burden as well [8]. Patients who are afflicted with an HCC arising from an

Prof. Dr. Andreas Schalhorn

Ludwig-Maximilians-Universität München, Medizinische Klinik und Poliklinik III Grosshadern, Marchioninistrasse 15, DE-81377 München (Germany)

Tel. +49897095 2250, Fax +498970952257

E-Mail andreas-schalhorn@med.uni-muenchen.de 
adenoma of the liver survive significantly longer than patients suffering an HCC evolving from a cirrhotic liver [9, 10].

Noteworthy, establishment of a diagnosis is difficult especially in patients with cirrhosis showing only small nodules [11]. In the absence of a definitive pathological statement, an elevated level of alpha fetoprotein together with nodules larger than $2 \mathrm{~cm}$ plus arterial hypervascularization in one imaging technique can lead to the establishment of the diagnosis ' $\mathrm{HCC}$ '. In $40 \%$ of all HCC, however, AFP at diagnosis is normal. Finally, the appearance of these nodules in two independent imaging techniques is considered sufficient for establishing the diagnosis as well [12]. The Barcelona Clinic Liver Cancer Staging Classification of patients with HCC (BCLC) is a staging nomenclature which is recommended by the American Association for the Study of Liver Diseases (AASLD) and the European Association for the Study of Liver Diseases (EASL) [13].

Detection at early stages (BCLC stage A) allows curative treatment by transplantation, resection or percutaneous ablation [2]. The optimum amongst these curative treatments is not established. Adjuvant chemoembolization or chemotherapy have failed to show beneficial effects after resection [2], yet promising results could be obtained using internal radiation with iodine-131-labelled lipiodol and interferon [14], adoptive immunotherapy by activated lymphocytes [15] and retinoids [16]. Percutaneous treatments administering chemical substances to or altering the temperature of the neoplastic cells have long been considered the best option for early detected though unresectable (BCLC stages B or C) HCC [17-20]. The median survival for patients with BCLC stage A, B, C or D tumors is 53, 16, 7 and 3 months, respectively [21]. In a recent phase III study [22], the group of patients receiving the orally available multikinase inhibitor sorafenib (Nexavar ${ }^{\circledR}$, Bayer) achieved a median time to progression of 5.5 months and an overall survival duration of 10.7 months. Overall survival in the verum group significantly exceeded overall survival in the placebo group (7.9 months). Sorafenib targets the Raf/MEK/ERK pathway at the level of the Raf kinase and blocks proliferation of HCC cells. It furthermore acts antiangiogenetically through the inhibition of the tyrosine kinases vascular endothelial growth factor receptor-2/ receptor-3 (VEGFR-2/-3) and platelet-derived growth factor receptor- $\beta$ (PDGFR- $\beta$ ). Overall survival in this study is not remarkably superior to the overall survival noted in other trials reporting about patients with BCLC stage B or C HCC [23]. The combination of sorafenib or different multikinase inhibitors or other antiangiogenetically active agents with cytotoxic therapy has to be tested against HCC in larger studies [24]. Further options for palliative treatment are (chemo)embolization [25-27], arterial [28] or systemic chemotherapy [27], internal radiation with ${ }^{131}$ I-lipiodol [29], hormonal compounds [30-38] and immunotherapy [39, 40]. A metaanalysis [2] of hormonal treatments with tamoxifen [3036] did not show any survival benefit. A meta-analysis [2] of arterial treatments ((chemo)embolization [41-47]) shows a survival benefit for well-selected patients and constitutes their standard treatment. Arterial embolization has been shown to lead to a partial response in 15-55 $\%$ [41-47] of patients. Furthermore, has it been shown to delay tumor progression and vascular invasion [43, 47]. Of seven randomized controlled clinical trials comparing chemoembolization with conservative management, survival benefits for chemoembolization could be found in two studies $[46,47]$. Chemoembolization seems beneficial for patients with a preserved liver function and asymptomatic nodular tumors without vascular invasion or extrahepatic spread. Liver decompensation or hepatic failure are contraindications against these options [43]. Anthracyclins have recently been published to show efficacy against HCC [48]. There is evidence against the use of paclitaxel in conventional formulations against HCC [49].

Taken together, with the exception of the success from the SHARP study [22], no sound data basis for the recommendation of one or the other palliative treatment option exists for patients not referable to chemoembolization. As is the case for many diseases in this palliative setting, novel treatment strategies are urgently warranted, especially taken into account the rising number of patients suffering from HCC. Strategies currently under observation include antiangiogenetic strategies. Thalidomide [50] and bevacizumab [51] are studied against a variety of neoplasms including HCC in increasing frequency. Data from studies of antiangiogenetic drugs against HCC are scarce and not convincing.

Here, we report encouraging results obtained using an experimental drug as fourth line palliative chemotherapy for a middle-aged European male patient suffering from a large multilocular HCC without extrahepatic spread and without signs of vascular invasion (BCLC stage B). This drug was designed as an antiangiogenic drug and is referred to as EndoTAG ${ }^{\circledR}$-1, originally named MBT-0206 or Lipopac ${ }^{\circledR}$. It is a save cationic liposomal formulation incorporating the cytostatic agent paclitaxel and has been developed to treat solid tumors. The drug directly targets 
the activated endothelial cells of the tumor vascular system [52]. These activated endothelia exhibit properties differing from the normal tissue vasculature, the most important being a negative surface charge of the endothelial cells as compared to quiescent endothelial cells in normal tissue. This negative charge marks a point of attack and accounts for the specific binding of the positively charged liposomes to endothelial cells in the vasculature of growing tumors. In the amelanotic hamster melanoma A-Mel-3, accumulation of cationic liposomes was preferred and enhanced in tumor vessels, well observed in the tumors and not seen in normal tissue [52, 53]. EndoTAG ${ }^{\circledR}-1$ effectively prevented melanoma growth and invasiveness, furthermore improved survival of the animals studied in a humanized SCID mouse model [54]. A significant retardation of melanoma growth in Syrian golden hamster by EndoTAG ${ }^{\circledR}-1$ could be observed even compared to free paclitaxel [55]. The general occurrence of angiogenesis in all solid tumors suggests a broad applicability of this concept. The enrichment of the drug in tumor tissue leads to a reduction of side effects due to the reduced exposure of healthy tissue to cytostatic agents. The manufacturer of EndoTAG ${ }^{\circledR}$-1, Medigene, has just reported on encouraging interim results from a phase II trial including 200 patients suffering inoperable, locally advanced or metastatic pancreatic carcinoma. In the group receiving the highest dose of EndoTAG ${ }^{\circledR}-1$ next to gemcitabine, survival exceeded survival of the control group (gemcibatine only) by $30 \%$.

We were encouraged to use EndoTAG ${ }^{\circledR}-1$ as fourthline therapy in a patient with progressive HCC.

\section{Case Report}

The patient was seeking medical advice in 1998 after experiencing pain under his right rip bow. A routine medical workup yielded multiple hypodensic lesions of the right lobe of the liver in ultrasonography and CT scan. Histology following right hemihepatectomy and resection of a further lesion in segment $\mathrm{V}$ which had been dectected intraoperatively confirmed the diagnosis of a large hepatocellular adenoma without any sign of malignancy. The pathologist described fatty degeneration of the liver cells and only partially regressive changes with slight cicatrisation in the adenoma but normal liver tissue without fatty degeneration in the physiological liver tissue at the borders of the tumor. Notably, the patient's AFP was slightly elevated at that time. Two years later, in March 2000, the patient experienced a new episode of pain under the right rib bow. Multiple heterogeneous lesions were detected in the patient's liver upon CT scan. They were highly suspicious of malignancy. Exploratory biopsy of these lesions resulted in the diagnosis of a HCC. The consulting surgeons assessed them as unresectable and the liver as nontransplantable. No risk factors for the development of liver cirrhosis or HCC were present in the patient's medical history. A CT scan 5 months later, a period during which the patient received $20 \mathrm{mg}$ tamoxifen twice daily, revealed progressive disease. The laboratory workup showed a normal AFP. The patient was subsequently referred to our outpatient clinic. First line chemotherapy consisted of intra-arterial regional folinic acid (300 mg, given over $1 \mathrm{~h}$ on days 1-5), 5-fluorouracil $\left(600 \mathrm{mg} / \mathrm{m}^{2}\right.$, equal to $1,000 \mathrm{mg}$ absolute dose, given over $2 \mathrm{~h}$ on days 1-5) and oxaliplatin (110 $\mathrm{mg}$ total dose, divided into two intra-arterial 4-hour infusions on days 2 and 4, respectively, of each treatment cycle), with repetition every 3 weeks. Ultrasound controls proved the treatment effective with partial remission. Unfortunately, this effective regional treatment had to be discontinued following occlusion of the hepatic artery after four cycles. Second-line chemotherapy consisted of intravenous oxaliplatin $\left(85 \mathrm{mg} / \mathrm{m}^{2}\right.$, equal to $140 \mathrm{mg}$, given over $2 \mathrm{~h}$ ) on day 1 , folinic acid $\left(500 \mathrm{mg} / \mathrm{m}^{2}\right.$, equal to $1,000 \mathrm{mg}$, given over $2 \mathrm{~h}$ ) and high dose 5 -fluorouracil $\left(2,000 \mathrm{mg} / \mathrm{m}^{2}\right.$, equal to $3,000 \mathrm{mg}$, given over $24 \mathrm{~h}$ ) on day 1 and day 8 . This therapy was repeated every 2 weeks. Two CT scans during this second line treatment revealed 'no change'. A slightly elevated AFP fell back to normal values. Oxaliplatin had to be discontinued in November 2001 following occurrence of severe bone pain. Folinic acid and 5-fluorouracil weekly were continued until a CT scan discovered progressive disease in March 2002. Third-line therapy was initiated: the patient was treated with liposomal adriamycin (Caelyx, $40 \mathrm{mg} / \mathrm{m}^{2}$, equal to $70 \mathrm{mg}$ ). This had to be halted after four cycles due to progressive disease as observed through computed tomography. After written informed and institutional consent were obtained, the patient was treated as a compassionate use case with liposomally encapsulated paclitaxel (EndoTAG $\left.{ }^{\circledR}-1\right)$. Treatment started in August 2002. The first dose consisted of $8 \mathrm{mg}$ total lipid per kg bodyweight and $0.29 \mathrm{mg} / \mathrm{kg}$ paclitaxel. The cytostatic content was stepwise enlarged up to $1.14 \mathrm{mg} / \mathrm{kg}$ paclitaxel, the total lipid content rose to $32 \mathrm{mg} / \mathrm{kg}$. In 39 doses of monotherapy, the infusion was started slowly and accelerated every $10 \mathrm{~min}$. Each application was preceded by intravenous administration of $20 \mathrm{mg}$ dexamethasone and histamine-blocking agents ( $\mathrm{H} 1$ and $\mathrm{H} 2$ antagonists). The first application was carried out in an intensive care unit to ensure maximal safety measurements. With only few exceptions, EndoTAG-1 was repeated weekly.

\section{Results}

\section{Safety}

During the first application no adverse effect occurred. Yet during the following days, the patient experienced fever for more than 1 day. His clinical status worsened slightly. After these symptoms had ceased, the administration of EndoTAG ${ }^{\circledR}-1$ was continued on the same dose level as during the first application and was as well tolerated as during the following 38 doses monotherapy. A dose escalation was performed as described above. 


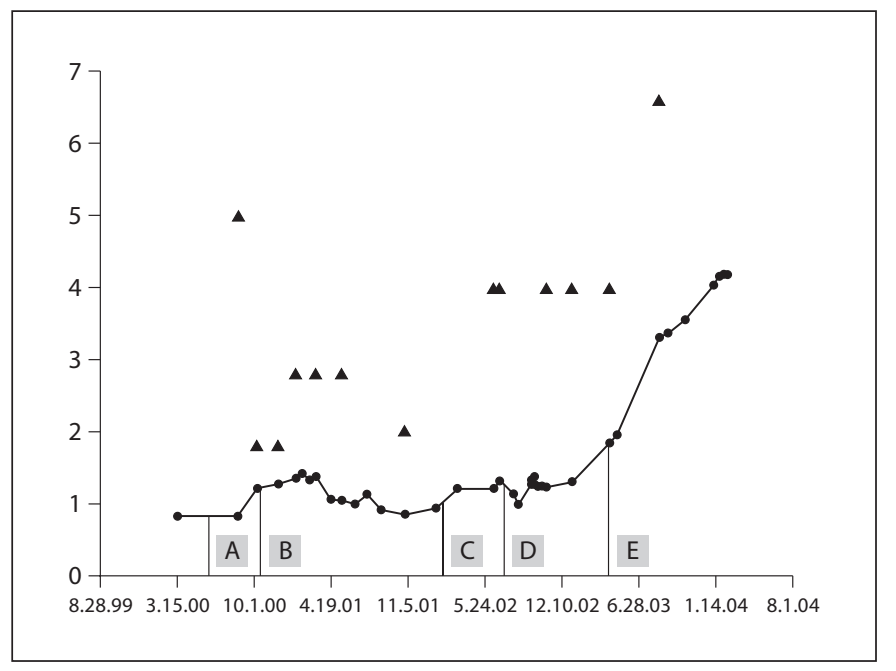

Fig. 1. Tumor marker (alpha-feto protein, AFP, logarithmic value, indicated by $\bullet$ ) and tumor size (diameter of one lesion in centimeters, indicated by $\mathbf{\Lambda}$ ) plotted against time. Chemotherapy given during the respective time is: A: intra-arterial folinic acid + 5-FU + oxaliplatin; B: intravenous folinic acid + HD 5-FU + oxaliplatin; C: caelyx; D: EndoTAG ${ }^{\circledR}-1$; E: EndoTAG ${ }^{\circledR}-1+$ carboplatin, later EndoTAG ${ }^{\circledR}-1$ + DTIC.

\section{Effects}

Surprisingly and most encouragingly, this drug arrested tumor growth as seen in computed tomography for 9 months until a massive progression was observed. The progression was evidenced through the worsening of the patient's clinical status and through CT scanning. Concomitantly, the AFP rose to values above $2,300 \mathrm{ng} / \mathrm{ml}$. The addition of carboplatin to the therapy had to be interrupted due to an acute adverse reaction and due to increased hematotoxicity in November 2003. The patient then was subdued to a combination of EndoTAG ${ }^{\circledR}-1$ and DTIC. After 3 months, the patient's tumor was progressive again in February 2004. One week later, the patient died. The time course is depicted in figure 1.

Of note, none of the drugs used is approved for use against HCC. There is no evidence for an optimal treatment against intermediate or advanced (BLCL stages B, C) HCC. Treatment in the case presented followed expert opinion.

\section{Conclusion}

Intermediate or advanced primary HCC is a disease without curative treatment options. Current therapeutic concepts consisting of chemotherapy, immunotherapy, local interventions or combinations of those fail to achieve convincing results. Novel interventions at BCLC stages B or $\mathrm{C}$ include kinase inhibitors like sorafenib and antiangiogenic strategies. Using this option, a median time to progression of 5.5 months and an overall survival of 10.7 months was achieved in a recent phase III study [22]. We successfully treated a patient with intermediate (BCLC stage B) and progressive HCC with paclitaxel encapsulated in cationic liposomes and achieved a time to progression of 9 months, exceeding the survival time achieved in the SHARP study of sorafenib monotherapy against HCC. It is believed that the specific formulation of this drug leads to specific adherence to the tumor's vasculature through physicochemical interactions, delivering the drug specifically to the tumor, furthermore starving the tumor through antiangiogenic actions. Paclitaxel itself has been studied without success against HCC [49]. Yet, in this situation the specific formulation of this drug and the drug itself showed efficacy.

Both options, the inhibition of many kinases in the tumor and the antiangiogenetic approach, we report on warrant studies in combinations with further cytostatic drugs and with each other. Notably, sorafenib is also reported to act against the formation of neovasculature. HCC are tumors showing a high degree of (neo)vasculature. Transcatheter arterial chemoembolization (TACE) is reported to further enhance this vascularization [56]. If combined with antiangiogenetic approaches, this might lead to an even higher degree of tumor starvation.

Albeit that HCC arising in the noncirrhotic liver, e.g. from an adenoma after a metabolic disease as in the case presented here, has a better survival compared to HCC arising in a cirrhotic liver $[9,10]$, the time to progression was measured starting at a very advanced stage of the disease where previous therapies failed to achieve a response. In general, low remission rates and usually rapid disease progression are observed with all drugs tested against intermediate and advanced HCC. Thus, a time to progression of 9 months even as fourth-line therapy is highly remarkable. This warrants phase II studies of EndoTAG ${ }^{\circledR}-1$ in HCC as well as in other solid tumors. The drug is currently tested in phase II trials against various types of solid tumors. Medigene, the manufacturer of EndoTAG ${ }^{\circledR}-1$, recently announced the interim results of EndoTAG ${ }^{\circledR}-1$ against inoperable, locally advanced or metastasized pancreatic cancer. In this study, gemcitabine monotherapy was randomized against different doses of EndoTAG ${ }^{\circledR}-1$ in combination with gemcitabine. Median survival in the group receiving the highest dose of EndoTAG ${ }^{\circledR}-1$ exceeded median survival of the control 
group by $30 \%$. Survival was even higher in patients who received EndoTAG ${ }^{\circledR}-1$ over a longer period and repeatedly. Results from a phase II study against hormone refractory breast cancer will be reported in 2009. In summary, the approach we present here should be tested early in the course of the disease in controlled studies against intermediate and advanced HCC.

\section{Conflict of Interest Statement}

K.B. and K.N. were employees of the former M.B.T. who developed the drug.

\section{References}

1 Parkin DM, Bray F, Ferlay J, Pisani P: Estimating the world cancer burden: Globocan 2000. Int J Cancer 2001;94:153-156.

2 Llovet JM, Burroughs A, Bruix J: Hepatocellular carcinoma. Lancet 2003;362:19071917.

3 Tanaka Y, Hanada K, Mizokami M, Yeo AE, Shih JW, Gojobori T, Alter HJ: Inaugural article: a comparison of the molecular clock of hepatitis $C$ virus in the United States and Japan predicts that hepatocellular carcinoma incidence in the United States will increase over the next two decades. Proc Natl Acad Sci USA 2002;99:15584-15589.

4 El Serag HB, Mason AC: Rising incidence of hepatocellular carcinoma in the United States. N Engl J Med 1999;340:745-750.

5 Chang MH, Chen CJ, Lai MS, Hsu HM, Wu TC, Kong MS, Liang DC, Shau WY, Chen DS: Universal hepatitis B vaccination in Taiwan and the incidence of hepatocellular carcinoma in children. Taiwan Childhood Hepatoma Study Group. N Engl J Med 1997;336: 1855-1859.

6 Chang MH, Shau WY, Chen CJ, Wu TC, Kong MS, Liang DC, Hsu HM, Chen HL, Hsu HY, Chen DS: Hepatitis B vaccination and hepatocellular carcinoma rates in boys and girls. JAMA 2000;284:3040-3042.

7 Manns MP, McHutchison JG, Gordon SC, Rustgi VK, Shiffman M, Reindollar R, Goodman ZD, Koury K, Ling M, Albrecht $\mathrm{JK}$ : Peginterferon alfa-2b plus ribavirin compared with interferon alfa-2b plus ribavirin for initial treatment of chronic hepatitis C: a randomized trial. Lancet 2001;358: 958-965.

8 Li Z, Li LJ, Sun Y, Li J: Identification of natural compounds with anti-hepatitis B virus activity from Rheum palmatum L. ethanol extract. Chemotherapy 2007;53:320-326.

9 Smalley SR, Moertel CG, Hilton JF, Weiland LH, Weiand HS, Adson MA, Melton LJ, III, Batts K: Hepatoma in the noncirrhotic liver. Cancer 1988;62:1414-1424.

10 Nzeako UC, Goodman ZD, Ishak KG: Hepatocellular carcinoma in cirrhotic and noncirrhotic livers: a clinico-histopathologic study of 804 North American patients. Am J Clin Pathol 1996;105:65-75.
11 Durand F, Regimbeau JM, Belghiti J, Sauvanet A, Vilgrain V, Terris B, Moutardier V, Farges O, Valla D: Assessment of the benefits and risks of percutaneous biopsy before surgical resection of hepatocellular carcinoma. J Hepatol 2001;35:254-258.

12 Bruix J, Sherman M, Llovet JM, Beaugrand M, Lencioni R, Burroughs AK, Christensen E, Pagliaro L, Colombo M, Rodes J: Clinical management of hepatocellular carcinoma. Conclusions of the Barcelona-2000 EASL Conference. European Association for the Study of the Liver. J Hepatol 2001;35:421430 .

13 Llovet JM, Bru C, Bruix J: Prognosis of hepatocellular carcinoma: the BCLC staging classification. Semin Liver Dis 1999;19:329-338.

14 Schwartz JD, Schwartz M, Mandeli J, Sung M: Neoadjuvant and adjuvant therapy for resectable hepatocellular carcinoma: review of the randomised clinical trials. Lancet Oncol 2002;3:593-603.

15 Takayama T, Sekine T, Makuuchi M, Yamasaki S, Kosuge T, Yamamoto J, Shimada K, Sakamoto M, Hirohashi S, Ohashi Y, Kakizoe T: Adoptive immunotherapy to lower postsurgical recurrence rates of hepatocellular carcinoma: a randomised trial. Lancet 2000;356:802-807.

16 Muto Y, Moriwaki H, Ninomiya M, Adachi S, Saito A, Takasaki KT, Tanaka T, Tsurumi K, Okuno M, Tomita E, Nakamura T, Kojima T: Prevention of second primary tumors by an acyclic retinoid, polyprenoic acid, in patients with hepatocellular carcinoma. Hepatoma Prevention Study Group. N Engl J Med 1996;334:1561-1567.

17 Lencioni R, Pinto F, Armillotta N, Bassi AM, Moretti M, Di Giulio M, Marchi S, Uliana M, Della CS, Lencioni M, Bartolozzi C: Longterm results of percutaneous ethanol injection therapy for hepatocellular carcinoma in cirrhosis: a European experience. Eur Radiol 1997;7:514-519.

18 Livraghi T, Giorgio A, Marin G, Salmi A, de S, I, Bolondi L, Pompili M, Brunello F, Lazzaroni S, Torzilli G: Hepatocellular carcinoma and cirrhosis in 746 patients: long-term results of percutaneous ethanol injection. Radiology 1995;197:101-108.
19 Rossi S, Di Stasi M, Buscarini E, Quaretti P, Garbagnati F, Squassante L, Paties CT, Silverman DE, Buscarini L: Percutaneous RF interstitial thermal ablation in the treatment of hepatic cancer. Am J Roentgenol 1996;167: 759-768.

20 Buscarini L, Buscarini E, Di Stasi M, Vallisa D, Quaretti P, Rocca A: Percutaneous radiofrequency ablation of small hepatocellular carcinoma: long-term results. Eur Radiol 2001;11:914-921.

21 Cillo U, Vitale A, Grigoletto F, Farinati F, Brolese A, Zanus G, Neri D, Boccagni P, Srsen N, D'Amico F, Ciarleglio FA, Bridda A, D'Amico DF: Prospective validation of the Barcelona Clinic Liver Cancer staging system. J Hepatol 2006;44:723-731.

22 Llovet JM, Ricci S, Mazzaferro V, Hilgard P, Raoul J, Zeuzem S, Poulin-Costello M, Moscovici M, Voliotis D, Bruix J, for the SHARP Investigators Study Group: Sorafenib improves survival in advanced hepatocellular carcinoma (HCC): results of a phase III randomized placebo-controlled trial (SHARP trial). J Clin Oncol ASCO Ann Meet Proc 2007;25(June 20 suppl): No 18S.

23 Yeo W, Mok TS, Zee B, Leung TW, Lai PB, Lau WY, Koh J, Mo FK, Yu SC, Chan AT, Hui P, Ma B, Lam KC, Ho WM, Wong HT, Tang A, Johnson PJ: A randomized phase III study of doxorubicin versus cisplatin/interferon alpha-2b/doxorubicin/fluorouracil (PIAF) combination chemotherapy for unresectable hepatocellular carcinoma. J Natl Cancer Inst 2005;97:1532-1538.

24 Richly H, Kupsch P, Passage K, Grubert M, Hilger RA, Voigtmann R, Schwartz B, Brendel E, Christensen O, Haase CG, Strumberg D: Results of a phase I trial of BAY 43-9006 in combination with doxorubicin in patients with primary hepatic cancer. Int J Clin Pharmacol Ther 2004;42:650-651.

25 Okamura J, Kawai S, Ogawa M, Ohashi Y, Tani M, Inoue J, Kawarada Y, Kusano M, Kubo Y, Kuroda C: Prospective and randomized clinical trial for the treatment of hepatocellular carcinoma: a comparison of $\mathrm{L}$ TAE with Farmorubicin and L-TAE with adriamycin (second cooperative study). The Cooperative Study Group for Liver Cancer Treatment of Japan. Cancer Chemother. Pharmacol 1992;31(suppl):S20-S24. 
26 Kawai S, Tani M, Okamura J, Ogawa M, Ohashi Y, Monden M, Hayashi S, Inoue J, Kawarada Y, Kusano M: Prospective and randomized clinical trial for the treatment of hepatocellular carcinoma: a comparison between L-TAE with farmorubicin and L-TAE with adriamycin. Preliminary results (second cooperative study). Cooperative Study Group for Liver Cancer Treatment of Japan. Cancer Chemother Pharmacol 1994;33 (suppl):S97-S102.

27 Kawai S, Tani M, Okamura J, Ogawa M, Ohashi Y, Monden M, Hayashi S, Inoue J, Kawarada Y, Kusano M, Kubo Y, Kuroda C, Sakata Y, Shimamura Y, Jinno K, Takahashi A, Takayasu K, Tamura K, Nagasue N, Nakanishi Y, Makino M, Masuzawa M, Yumoto Y, Mori T, Oda T: Prospective and randomized trial of lipiodol-transcatheter arterial chemoembolization for treatment of hepatocellular carcinoma: a comparison of epirubicin and doxorubicin (second cooperative study). The Cooperative Study Group for Liver Cancer Treatment of Japan. Semin Oncol 1997;24:S6-S6.

28 Pohlen U, Berger G, Reszka R, Binnenhei M, Buhr HJ: Improved tumor targeting by regional carboplatin application combined with Gelfoam: an experimental study on liver tumor-bearing rabbits. Chemotherapy 2001;47:143-149.

29 Raoul JL, Guyader D, Bretagne JF, Heautot JF, Duvauferrier R, Bourguet P, Bekhechi D, Deugnier YM, Gosselin M: Prospective randomized trial of chemoembolization versus intra-arterial injection of ${ }^{131}$ I-labeled-iodized oil in the treatment of hepatocellular carcinoma. Hepatology 1997;26:1156-1161.

30 Elba S, Giannuzzi V, Misciagna G, Manghisi OG: Randomized controlled trial of tamoxifen versus placebo in inoperable hepatocellular carcinoma. Ital J Gastroenterol 1994; 26:66-68.

31 Martinez Cerezo FJ, Tomas A, Donoso L, Enriquez J, Guarner C, Balanzo J, Martinez NA, Vilardell F: Controlled trial of tamoxifen in patients with advanced hepatocellular carcinoma. J Hepatol 1994;20:702-706.

32 Castells A, Bruix J, Bru C, Ayuso C, Roca M, Boix L, Vilana R, Rodes J: Treatment of hepatocellular carcinoma with tamoxifen: a double-blind placebo-controlled trial in 120 patients. Gastroenterology 1995; 109:917922.

33 Manesis EK, Giannoulis G, Zoumboulis P, Vafiadou I, Hadziyannis SJ: Treatment of hepatocellular carcinoma with combined suppression and inhibition of sex hormones: a randomized, controlled trial. Hepatology 1995;21:1535-1542.

34 Tamoxifen in treatment of hepatocellular carcinoma: a randomised controlled trial. CLIP Group (Cancer of the Liver Italian Programme). Lancet 1998;352:17-20.
35 Riestra S, Rodriguez M, Delgado M, Suarez A, Gonzalez N, de la MM, Diaz G, Mino-Fugarolas G, Rodrigo L: Tamoxifen does not improve survival of patients with advanced hepatocellular carcinoma. J Clin Gastroenterol 1998;26:200-203.

36 Liu CL, Fan ST, Ng IO, Lo CM, Poon RT, Wong J: Treatment of advanced hepatocellular carcinoma with tamoxifen and the correlation with expression of hormone receptors: a prospective randomized study. Am J Gastroenterol 2000;95:218-222.

37 Chow PK, Tai BC, Tan CK, Machin D, Win KM, Johnson PJ, Soo KC: High-dose tamoxifen in the treatment of inoperable hepatocellular carcinoma: a multicenter randomized controlled trial. Hepatology 2002;36: 1221-1226.

38 Villa E, Ferretti I, Grottola A, Buttafoco P, Buono MG, Giannini F, Manno M, Bertani H, Dugani A, Manenti F: Hormonal therapy with megestrol in inoperable hepatocellular carcinoma characterized by variant oestrogen receptors. Br J Cancer 2001;84:881-885.

39 Lai CL, Lau JY, Wu PC, Ngan H, Chung HT, Mitchell SJ, Corbett TJ, Chow AW, Lin HJ: Recombinant interferon-alpha in inoperable hepatocellular carcinoma: a randomized controlled trial. Hepatology 1993; 17:389394.

40 Llovet JM, Sala M, Castells L, Suarez Y, Vilana R, Bianchi L, Ayuso C, Vargas V, Rodes J, Bruix J: Randomized controlled trial of interferon treatment for advanced hepatocellular carcinoma. Hepatology 2000;31: 54-58.

41 Lin DY, Liaw YF, Lee TY, Lai CM: Hepatic arterial embolization in patients with unresectable hepatocellular carcinoma: a randomized controlled trial. Gastroenterology 1988;94:453-456.

42 Pelletier G, Roche A, Ink O, Anciaux ML, Derhy S, Rougier P, Lenoir C, Attali P, Etienne JP: A randomized trial of hepatic arterial chemoembolization in patients with unresectable hepatocellular carcinoma. J Hepatol 1990;11:181-184.

43 A comparison of lipiodol chemoembolization and conservative treatment for unresectable hepatocellular carcinoma. Groupe d'Etude et de Traitement du Carcinome Hepatocellulaire. N Engl J Med 1995;332:12561261.

44 Bruix J, Llovet JM, Castells A, Montana X, Bru C, Ayuso MC, Vilana R, Rodes J: Transarterial embolization versus symptomatic treatment in patients with advanced hepatocellular carcinoma: results of a randomized, controlled trial in a single institution. Hepatology 1998;27:1578-1583.

45 Pelletier G, Ducreux M, Gay F, Luboinski M, Hagege H, Dao T, Van Steenbergen W, Buffet C, Rougier P, Adler M, Pignon JP, Roche A: Treatment of unresectable hepatocellular carcinoma with lipiodol chemoembolization: a multicenter randomized trial. Groupe CHC. J Hepatol 1998;29:129-134.
46 Lo CM, Ngan H, Tso WK, Liu CL, Lam CM, Poon RT, Fan ST, Wong J: Randomized controlled trial of transarterial lipiodol chemoembolization for unresectable hepatocellular carcinoma. Hepatology 2002;35:11641171.

47 Llovet JM, Real MI, Montana X, Planas R, Coll S, Aponte J, Ayuso C, Sala M, Muchart J, Sola R, Rodes J, Bruix J: Arterial embolisation or chemoembolisation versus symptomatic treatment in patients with unresectable hepatocellular carcinoma: a randomised controlled trial. Lancet 2002;359:1734-1739.

48 Pohl J, Zuna I, Stremmel W, Rudi J: Systemic chemotherapy with epirubicin for treatment of advanced or multifocal hepatocellular carcinoma. Chemotherapy 2001 47:359365.

49 Chao Y, Chan WK, Birkhofer MJ, Hu OY, Wang SS, Huang YS, Liu M, Whang-Peng J, Chi KH, Lui WY, Lee SD: Phase II and pharmacokinetic study of paclitaxel therapy for unresectable hepatocellular carcinoma patients. Br J Cancer 1998;78:34-39.

50 Yau T, Chan P, Wong H, Ng KK, Chok SH, Cheung TT, Lam V, Epstein RJ, Fan ST, Poon RT: Efficacy and tolerability of low-dose thalidomide as first-line systemic treatment of patients with advanced hepatocellular carcinoma. Oncology 2007;72(suppl 1):67-71.

51 Zhu AX, Holalkere NS, Muzikansky A, Horgan K, Sahani DV: Early antiangiogenic activity of bevacizumab evaluated by computed tomography perfusion scan in patients with advanced hepatocellular carcinoma. Oncologist 2008;13:120-125.

52 KrasniciS, Werner A, Eichhorn ME, SchmittSody M, Pahernik SA, Sauer B, Schulze B, Teifel M, Michaelis U, Naujoks K, Dellian M: Effect of the surface charge of liposomes on their uptake by angiogenic tumor vessels. Int J Cancer 2003; 105:561-567.

53 Eichhorn ME, Strieth S, Krasnici S, Sauer B, Teifel M, Michaelis U, Naujoks K, Dellian M: Protamine enhances uptake of cationic liposomes in angiogenic microvessels. Angiogenesis 2004;7:133-141.

54 Kunstfeld R, Wickenhauser G, Michaelis U, Teifel M, Umek W, Naujoks K, Wolff K, Petzelbauer P: Paclitaxel encapsulated in cationic liposomes diminishes tumor angiogenesis and melanoma growth in a 'humanized' SCID mouse model. J Invest Dermatol 2003;120:476-482.

55 Schmitt-Sody M, Strieth S, Krasnici S, Sauer B, Schulze B, Teifel M, Michaelis U, Naujoks K, Dellian M: Neovascular targeting therapy: paclitaxel encapsulated in cationic liposomes improves antitumoral efficacy. Clin Cancer Res 2003;9:2335-2341.

56 Sergio A, Cristofori C, Cardin R, Pivetta G, Ragazzi R, Baldan A, Girardi L, Cillo U, Burra P, Giacomin A, Farinati F: Transcatheter arterial chemoembolization (TACE) in hepatocellular carcinoma (HCC): the role of angiogenesis and invasiveness. Am J Gastroenterol 2008;103:914-921. 